\title{
The utility of delayed-enhancement and t2-weighted cardiovascular mri for predicting clinical outcomes in patients at high risk for cardiac sarcoidosis
}

Yongkasem Vorasettakarnkij ${ }^{*}$, Hector M Medina², Waleed Ahmed², Godtfred Holmvang ${ }^{3}$, Peerawut Deeprasertkul ${ }^{2}$, Daniel J Verdini ${ }^{2}$, Shanmugam Uthamalingam² ${ }^{2}$ Thomas J Brady², Brian B Ghoshhajra², David E Sosnovik ${ }^{1}$

From 2011 SCMR/Euro CMR Joint Scientific Sessions

Nice, France. 3-6 February 2011

\section{Purpose}

To evaluate the utility and prognostic value of delayed enhancement and T2 weighted cardiovascular MRI in patients at high risk for cardiac sarcoidosis.

\section{Introduction}

The utility of delayed-enhancement (DE) has been extensively studied in patients with sarcoidosis who are asymptomatic or at low risk for cardiac involvement. However, there is lack of data regarding the utility of DE in patients with sarcoidosis who present with high grade cardiovascular symptoms. Also, the utility of T2-weighted imaging has not been evaluated in these patients.

\section{Methods}

Patients referred for cardiac MRI (CMR) from 01/01/ 2003 to $12 / 31 / 2009$ in our institution, and who had biopsy proven sarcoidosis without concomitant coronary artery disease, were included. Patients were classified as presenting with a major rhythmic disturbance (MRD) if the referral for cardiac MRI was prompted by high grade atrio-ventricular block, sustained ventricular tachycardia or ventricular fibrillation. Mean duration of follow up after MRI was $20.7+13.8$ months.

\section{Results}

Forty patients with sarcoidosis referred for CMR met entry criteria. $8 / 40(20 \%)$ patients experienced a MRD

\footnotetext{
'Martinos Center for Biomedical Imaging, Massachusetts General Hospital, Harvard Medical School, Charlestown, MA, USA
}

prior to CMR. Of these, $8 / 8(100 \%)$ patients demonstrated hyper-enhancement and 4/8 (50\%) had hyperintensity on T2W-CMR. During follow-up, 8/8 (100\%) had recurrent MRD or required permanent pacemaker implantation. DE of a patient presenting with complete heart block is shown in Figure 1. In the 32/40 (80\%) patients without an MRD prior to MRI, 11 (34\%) demonstrated hyperenhancement on DE-MRI. From these, 3/11 (27\%) also had hyper-intensity on

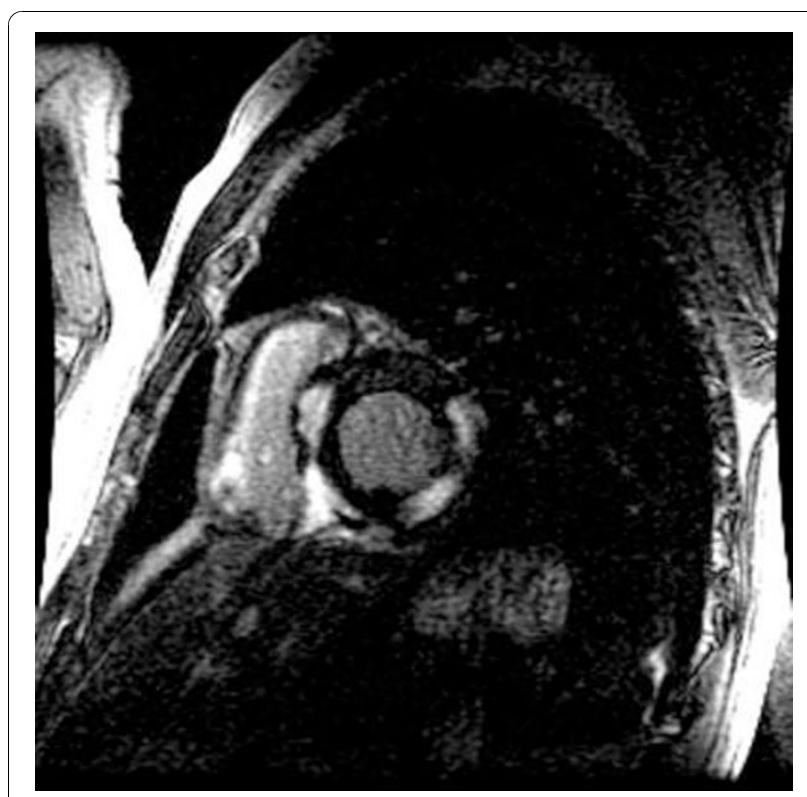

Figure 1 Delayed-enhancement of a patient presenting with complete heart block. 
T2W-CMR. In 21/40 (53\%) patients presenting without a prior MRD and no delayed enhancement, T2WCMR was negative in all cases. None of these 21 patients had a MRD during follow-up.

\section{Conclusions}

In patients with suspected cardiac sarcoidosis who present with a MRD, DE-CMR is extremely likely to be positive and is helpful in confirming cardiac involvement. These patients are highly likely to experience recurrent adverse events regardless of the presence or absence of acute edema or inflammation on MRI. Patients without a prior MRD who show no evidence of delayed enhancement by CMR have an excellent prognosis and are at very low risk of developing a MRD within next year. A history of a prior MRD is the strongest predictor of a future MRD. CMR, however, has a valuable role to play in confirming the diagnosis and refining risk, particularly in those presenting without a prior MRD.

\section{Author details}

'Martinos Center for Biomedical Imaging, Massachusetts General Hospital, Harvard Medical School, Charlestown, MA, USA. ${ }^{2}$ Cardiac MRI/PET/CT program, Department of Radiology, Massachusetts General Hospital, Harvard Medical School, Boston, MA, USA. ${ }^{3}$ Cardiology Division, Massachusetts General Hospital, Harvard Medical School, Boston, MA, USA.

Published: 2 February 2011

doi:10.1186/1532-429X-13-S1-0105

Cite this article as: Vorasettakarnkij et al:: The utility of delayedenhancement and t2-weighted cardiovascular mri for predicting clinical outcomes in patients at high risk for cardiac sarcoidosis. Journal of Cardiovascular Magnetic Resonance 2011 13(Suppl 1):0105.
Submit your next manuscript to BioMed Central and take full advantage of:

- Convenient online submission

- Thorough peer review

- No space constraints or color figure charges

- Immediate publication on acceptance

- Inclusion in PubMed, CAS, Scopus and Google Scholar

- Research which is freely available for redistribution

Submit your manuscript at www biomedcentral.com/submit 